\title{
Students' Utilization of Distance Learning through an Interventional Online Module Based on Moore Transactional Distance Theory
}

\author{
Hassan Abuhassna ${ }^{1 *}$, Noraffandy Yahaya ${ }^{1}$ \\ ${ }^{1}$ Faculty of Education, University Technology Malaysia, MALAYSIA
}

Received 17 February 2018 - Revised 14 March 2018 - Accepted 6 April 2018

\begin{abstract}
Introduction: Online learning platforms potentially increase student engagement and interactivity, thus contributing toward enhancing students' satisfaction with distance learning. The main aim of this research is to investigate the efficacy of an interventional online module based on Moore transactional distance theory on students' learning autonomy and satisfaction regarding the utilization of distance learning.
\end{abstract}

Materials and Methods: An experimental design was conducted with a stratified random sample of 100 students (50 control and 50 intervention) from the University College of Applied Sciences, Palestine. Three tools were applied in this study: the DELES instrument, which was given to the intervention group, another validated tool that was given to the control group and an achievement test that was introduced to both groups. The intervention included educational and training sessions that were given in the environment of online learning after the student's baseline assessment.

Results: It was noted that there was a significance difference in the domain of instructor support before and after the intervention within the intervention group. It was also observed that there was no significant difference (NSD) in the mean scores for students' collaboration and interaction, satisfaction and learning autonomy within the intervention group before and after the intervention. Moreover, there was NSD in mean scores for remembering, understanding or application among two groups (control and intervention) before and after the intervention, whereas it was a significant difference in the mean analysis score among the intervention and the control group before and after the intervention.

Keywords: distance learning, Moore theory, transnational distance theory, Moodle

\section{INTRODUCTION}

Many people have negative perceptions and conceptions about distance learning education, considering it to be poor in performance. Yet new tools and techniques such as distance learning, web-based courses, learning management systems (LMS) and Moodle are making significant contributions in the distance learning arena and increasing students' satisfaction (Ali, 2011). Distance learning is not a new concept, and nor is research on this topic (Means, Toyama, Murphy \& Baki, 2013; Simonson, Schlosser \& Orellana, 2011; Zhao, Lei, Yan, Lai \& Tan, 2005). Although distance and online learners have faced many challenges historically, such as impersonal interactions and unsatisfying, (Lee, Srinivasan, Trail, Lewis \& Lopez, 2011; Paechter, Maier \& Macher, 2010; Song, Singleton, Hill \& Koh, 2004; Vonderwell, 2003). Still the number of students signing up for distance learning courses has increased dramatically over the past thirty years. With the rapid expansion and increasing availability of material and communication technologies, distance learning courses have continued to improve, and new methods have been developed.

(C) 2018 by the authors; licensee Modestum Ltd., UK. This article is an open access article distributed under the terms and conditions of the Creative Commons Attribution License (http://creativecommons.org/licenses/by/4.0/). \.v79@live.com hashas10@gmail.com (*Correspondence) $\square$ fandymcl@gmail.com 


\section{Contribution of this paper to the literature}

- Transactional distance theory of distance learning was the theoretical frame work for this study.

- An interventional module including both online and face to face courses were conducted.

- This research is the first to be conducted in the Gaza strip regarding distance learning.

Moreover, distance learning is not a new fact phenomenon, its popularity has increased the interest and visibility in distance learning as a new method of research and learning to enhance the audiences (Gasevic, Kovanovic, Joksimovic \& Siemens, 2014). In addition, the line between distance education and traditional education has become blurred, as many establishments have incorporated blended learning into their programs and courses. Some on-campus classes, using a blended approach, also incorporate opportunities for online discussions so that student conversations can continue beyond the classroom (Jacobs, Renandya, \& Power, 2016). Online learning platforms can potentially increase student engagement and interactivity, thus contributing toward enhancing students' satisfaction with distance learning (Garrison, 2011; Harasim, 2012). The issue to be explored here is the design and structure of online discussion, and attention also needs to be given to the course design and the management process of the course, and the construction of activities and organizational structures that lead to a proper environment for distance learning. Identifying the extent to which online interactions demonstrate meaningful student learning becomes crucial to understanding the learning potential that is afforded through such things as online discussion forums.

Online course design based on Moodle provides a variety of tools to students such as email (asynchronous), chat rooms (synchronous), discussion forums and course content spaces: these features offer students a range of interactive opportunities, including student-to-content, student-to-instructor interaction and student-to-student (Moore \& Kearsley, 2005). As a learning platform, Moodle can enhance the learning environment (Stanley \& Adam 2014). In addition, this platform has an extended range of criteria along with useful features, such as offering access to the web-based environment from any location, a day of 24 hours, a week of 7 days, so that student can get instructions, submit and compose their assignments, ask their instructors questions and discuss issues with their fellow students with the help of internet connections (Gartner, 2014). The purpose for this research was to highlight the connection between distance learning and students' achievement, along with their autonomy and satisfaction in the distance learning field. The research was conducted at the Applied Science University in Gaza Strip, Palestine.

Students' performance was considered as the dependent variable and tutorial meetings, assignments and faceto-face sessions were considered as independent variables. The researcher developed an internet course via the Moodle system based on the transactional distance theory of Moore. The target population for this research was ASU students studying Applied Teaching Systems, and the sample comprised 100 students from Applied Science University in Gaza. A self-managed questionnaire study was used for data collection through convenience sampling and non-probability sampling. The research supports the hypotheses that tutorial meetings and assignments have the strongest and most significant impact on students' performance.

\section{BACKGROUND}

\section{Theoretical Framework}

Moore's Transactional Distance theory considered as a theoretical framework to design this research. Moore (1983) developed this theory of distance learning programs to investigate two variables: students' autonomy and the distance between students and teachers (Hanson et al., 1997). Transitional Distance theory mainly describes the learner and the educator/teacher relationship. The transactional distance is essential, according to Moore's understanding, because the perception is grounded in distance learning within a social structure, not in its traditional form. The second element of Moore's theory involves the autonomy of the student, as the distance between him and his teacher means that the student must adopt responsibility for his own learning.

Moore (1997) summarized distance learning interaction by describing three forms of interaction:

i. Learner-content interaction: Students can get information from the course contents using this method. The contents may be in the form of text, video or audio, online communication, computer-aided programs or CD-ROM.

ii. Learner-learner interaction: This kind of interaction is used for the exchange of ideas and information about the course that arises among students in the absence or presence of the teacher. This kind of interaction may appear in the form of group discussion, group projects, etc. It can promote learning via sharing of knowledge and student collaboration. 
iii. Learner-instructor interaction: This is related to the instructor and the learner communication. It may appear in the form of an instructor conveying information, inspiring the learner, or giving feedback. Additionally, it may incorporate the learner's interaction with the teacher by communicating or asking questions related to course exercises.

Moore's interaction theory has been adapted and extended. For example, Hillman, Willis and Gunawardena (1994) included learner-interface interaction "it is another form of interaction and an operating tools procedure to achieve a task". Sutton (2001), on the other hand, included indirect interaction: "Indirect interaction occurs when a certain learner supervises actively a certain interaction between other learners and the instructor or between another two learners". The adoption and extension of interaction theory emphasizes the influence and impact of Moore's work upon technology research in education with the growth of online learning.

The researcher believes that the key challenge for teachers in a distance learning is the process of applying the distance learning and its theoretical basis, as many are unsure about how to go through this process with confidence. A theoretical framework can be seen as a means to predict what to expect in distance learning under particular conditions and circumstances, thus providing enhanced practical application. Moore's position as a bigger in distance learning is clear, along with his contribution as the main founder of distance learning. Practitioners of educational technology in distance learning have access to important scholarly interaction. Moore's theories about distance learning and his contributions to scholarship and practice have influenced numerous instructive technologists in significant ways.

This study was set out to develop student satisfaction regarding distance learning courses in the Gaza strip, where there is a lack of researches has been focused in the area of distance learning, as this study is the first to be conducted in the Gaza higher education.

\section{LITERATURE REVIEW}

Discussing the studies conducted in distance learning field enrich this study's literature for many reasons. (1) Obtaining and knowing better perceptions on the history of distance learning. (2) To provide the criticisms needed for providing future studies, as the urgent necessity to have researches and practices for distance learning high quality.

Considerable amount of studies has clarified the strong connection between the student interaction, and their roles in enhancing achievements in distance learning e.g., Bryant \& Bates (2015), Yang, Yu, Chen, and Huang (2014). Normally, interaction has three elements or forms: 1) learner-educator interaction; 2) learner-learner interaction; and 3) learner-content interaction. The interactions between learner-educator can be synchronous or asynchronous as viewed above, with the educator's delivering the knowledge, easing the learning process, question answering, and giving the needed feedback.

The research findings of Mahle (2011) recommended that the student satisfaction and interaction may have dependent relationship. Satisfaction happens when it is comprehended performance meets learners' expectations and considered a short-term attitude about the learning process. High education satisfaction researchers concentrate on the distribution and operational side of the learner's experience in the teaching process. The feedback of the learners can affect the course delivering and areas in which it might enhanced.

Results in the researchers conducted by Bordelon (2013) reported and concluded a positive relationship between both achievement and satisfaction. Bordelon indicated that reason behind such results, might be cultural differences in learners' satisfaction that indicates learning accession Zhu (2012). In addition, due to previous factors such as the service performance, universities performance, relationships and university standing. Although satisfaction was not related in an explicit way to the achievements of the learners, it is a statement of confidence in the system and the trust combined within, its importance cannot be overruled.

Ekwunife-Orakwue and Teng (2014) found that there was not such a noticeable distinctive comparison between online, blended and traditional environments. However, they recommend blended and online courses with few direct meetings, as this could benefit the student more than the archived lecturer.

\section{MATERIALS AND METHODS}

\section{Study Design}

This study adopted an experimental design. Two groups were made for participants, the first is a control group, it did not receive the intended interference, the $2^{\text {nd }}$ is an intervention group, it received the proposed intervention, including the post and pre-Questionnaire and the post and pre-achievement test to triangulate the data. 


\section{Sample and Sampling}

To eliminate the source of bias in treatment assignments, a stratified random sampling method was applied to recruit 100 students. The sample included students in the first and second year at the University College of Applied Sciences (UCAS) who were registered for the Educational Psychology course. Twenty-four (48.0\%) of the students who joined the intervention group were male and 26 (52.0\%) were female. The sample size was calculated using power-sample size software and in consultation with a statistician. The participants were selected from the Department of Education at UCAS because it is the biggest department in the college, with many students. Moreover, the Educational Psychology course is one of the compulsory courses listed in the Department of Education.

\section{MOODLE's Importance}

Moodle is a free web application, which helps both teachers and educators to create and develop online courses. As a learning platform, Moodle can enhance the learning environments Stanley (2014). In addition, this platform has an extended range of criteria along with great features Gartner (2012). Moodle can be utilized in many environments forms, as an open source, which helps developers to create and edit this environment based on their own needs and desires. Developers and users have the free choice to update, purchase tools, or determine how courses and websites should possess based on their desires.

Martin Dougiamas developed this system, and he managed to create a device with technological characteristics along with pedagogical satisfactory Moodle Partners (2016). Users and programmers working collaboratively within their special environments like Moodle has been elevated. Moodle's great achievement is because it allowed the viability and the ability to reach the system anywhere in the world, making the system as one of the most system used to manage courses at distance. Moodle has been translated into over 100 different languages and is accessible in many countries worldwide (Language packs - Moodle Docs). In addition, it has been used as a platform within an extended range of companies all around the world, in order to create online courses.

\section{TOOLS AND DATA COLLECTION}

A web-based measure, namely the "Distance Education Learning Environments Survey" (DELES: Walker \& Fraser, 2005), has been selected for use in this research because it emphasizes the environment of students' learning perceptions to the elimination of technical issues, such as learning platforms or internet access, as found in other tools for examining distance learning environments.

Certain modifications were made to the DELES instrument and it was then validated again. The framework for this research is Moore's TDT. DELES was made to analyze the perceptions of students about their distance education social environment through six scales: students' authentic learning, consisting of five items; interaction and collaboration, containing six items; support of instructor, containing eight items; student autonomy, containing ten items; personal relevance, containing seven items; and active learning, containing five items. The original fivepoint scale (never, seldom, sometimes, often and always) was retained. The DELES tool was given to the experimental group, while another suitable validated tool that the researcher has developed was given to the control group: the DELES tool was not suitable for this group, since they were not receiving courses via distance/online learning.

Moreover, an achievement test was developed for this study by an expert in educational psychology. The achievement test was applied before and after the intervention: this test, which has previously been shown to be valid and reliable, was introduced to both groups at the same time. The achievement test was carried out to identify the extent of the study participants' actual response to the proposed intervention, thus providing support for the study results and demonstrating that the students within the intervention group achieved the same scores as those in the control group. The validated achievement test consisted of four domains, namely: 1) remembering, 2) understanding, 3) application, and 4) analysis. Each domain consisted of questions which reflect the nature and process of domain measurement, and this test had a total of forty questions.

\section{INTERVENTION STRATEGY}

Educational and training sessions were given in the online learning field after the baseline assessment of students. Two sessions were conducted face-to-face to introduce the students to distance learning and Moodle. The educational training sessions were given in class time during Educational Psychology classes twice a week, included information about video conferencing use and the importance of distance learning strategies. The lectures also included videos and materials that demonstrated appropriate ways of participation in online classes, creating successful student-student and student-lecturer dialogue. 
Table 1. Baseline comparison of mean scores for student satisfaction, interaction and collaboration, instructor support and learning autonomy

\begin{tabular}{ccccc}
\hline Domain & Intervention & Control & \multirow{2}{*}{ t statistics (df) } & \multirow{2}{*}{$\boldsymbol{p}$ value } \\
\cline { 2 - 3 } & Mean (SD) & Mean (SD) & & \\
\hline Instructor support & $1.91(1.03)$ & $2.11(0.66)$ & $1.149(83.15)$ & 0.254 \\
\hline $\begin{array}{c}\text { Student satisfaction, Interaction } \\
\text { and Collaboration }\end{array}$ & $2.32(0.87)$ & $2.60(0.55)$ & $1.868(82.87)$ & 0.065 \\
\hline Learning autonomy & $2.13(0.95)$ & $2.38(0.68)$ & $1.491(88.89)$ & 0.140 \\
\hline
\end{tabular}

*Independent sample $t$ test

$\mathrm{SD}=$ Standard Deviation

$\mathrm{df}=$ Degree of Freedom

Table 2. Comparison of student satisfaction, interaction and collaboration, instructor support and learning autonomy inside groups based on time $(n=100)$

\begin{tabular}{|c|c|c|c|c|c|c|}
\hline \multirow{2}{*}{ Measurement level } & \multicolumn{3}{|c|}{ Intervention Group $(n=50)$} & \multicolumn{2}{|c|}{ Control Group $(n=50)$} & \multirow[b]{2}{*}{$P$ Value } \\
\hline & MD (C.I. 95\%) & $F$ statistics (df) & $p$-Value ${ }^{*}$ & MD (C.I. 95\%) & $F$ statistics (df) & \\
\hline \multicolumn{7}{|l|}{ Instructor support } \\
\hline $\begin{array}{c}\text { PRE-POST } \\
\text { intervention }\end{array}$ & $\begin{array}{c}-0.603(-1.001,- \\
0.205)\end{array}$ & $9.280(1,49)$ & 0.004 & $0.183(-0.203,0.568)$ & $0.905(1,49)$ & 0.346 \\
\hline \multicolumn{7}{|l|}{ Learning autonomy } \\
\hline $\begin{array}{c}\text { PRE-POST } \\
\text { intervention }\end{array}$ & $0.056(-0.243,0.355)$ & $0.143(1,49)$ & 0.707 & $-0.090(-.0311,0.131)$ & $0.672(1,49)$ & 0.416 \\
\hline \multicolumn{7}{|c|}{ Student satisfaction } \\
\hline $\begin{array}{c}\text { PRE-POST } \\
\text { intervention }\end{array}$ & $0.007(-0.124,0.139)$ & $0.013(1,49)$ & 0.910 & $0.158(0.003,0.314)$ & $4.171(1,49)$ & 0.047 \\
\hline
\end{tabular}

One-way ANOVA with Repeated Measurements was applied inside group analysis, subsequently Pairwise Comparison with confidence interval settings.

* Pairwise comparison with Bonferroni correction to correct the significance level.

$M D=$ Mean Difference.

PRE $=$ Baseline measures of mean variables

POST $=$ Mean variables measurement after 6 months

$\mathrm{df}=$ Degree of Freedom

$\mathrm{Cl}=$ Confidence Interval

The study was then carried out for eight weeks through a web-based course that was designed for this study using Moodle. The course was designed based on Moore's transactional distance theory. Most of the sessions lasted for approximately 45 minutes. Training sessions emphasized several issues, such as: i) introducing educational psychology, ii) educational psychology theories, iii) psychology in education, and iv). Exercises were also provided. After the completion of the education and training program, each student was given a written handbook, presentation handouts and a video $\mathrm{CD}$ and materials to help in absorbing the lectures information. In this study, the intervention program is an evidence-based approach regarding online learning in education.

\section{RESULTS}

Table 1 demonstrates that there are NSD in any of the domains (interaction and collaboration, support of instructor, student satisfaction and learning autonomy) between the control and the intervention group at baseline measurement $(\mathrm{p}>0.050)$.

The study results showed that the mean score for instructor support was lower at pre-intervention (1.91) than at post intervention (2.52). It was observed a significant difference in the mean score for instructor support inside the group intervention as revealed in Table 2 (correction as per Huynh-Feldt, $\mathrm{F}=9.280, p<0.05$ ). The post- and preintervention results show that the mean score for instructor support was lower at post-intervention (2.32) than at pre-intervention (2.31). It was also observed that there was NSD in the mean scores for student satisfaction, interaction and collaboration within the intervention group (correction as per Huynh-Feldt, $\mathrm{F}=0.013, p>0.05$ ).

Moreover, the post- and pre-intervention findings recommended that the mean score for learning autonomy was lower at post-intervention (2.08) than at pre-intervention (2.13). It was observed that there was NSD in the mean score for learning autonomy within the group intervention (correction as per Huynh-Feldt, $\mathrm{F}=0.143, p>0.05$ : see Table 2). 
Table 3. Mean difference in remembering, understanding, application and analysis before and after the intervention among the intervention and the control group: between-groups effect $(n=100)$

\begin{tabular}{cccc}
\hline Comparison & MD (C.I 95\%) & F statistics (df) & p-value \\
\hline $\begin{array}{c}\text { Control - Intervention } \\
\text { Remembering }\end{array}$ & $-4.120(-4.420,-3.320)$ & $0.046(1)$ & 0.831 \\
\hline $\begin{array}{c}\text { Control - Intervention } \\
\text { Understanding }\end{array}$ & $-4.990(-5.316,-4.664)$ & $0.000(1)$ & 0.983 \\
\hline $\begin{array}{c}\text { Control - Intervention } \\
\text { Application }\end{array}$ & $-1.200(-1.375,-1.025)$ & $0.023(1)$ & .0880 \\
\hline $\begin{array}{c}\text { Control - Intervention } \\
\text { Analysis }\end{array}$ & $-2.410(-2.690,-2.130)$ & $4.343(1)$ & 0.040 \\
\hline
\end{tabular}

One-Way Repeated Measures ANOVA was applied within group analysis

MD = Mean Difference.Significance level was adjusted at 0.05 I (two-tailed)

$\mathrm{df}=$ Degree of Freedom

Regarding the achievement test, the results showed NSD in mean remembering, understanding, or application between two groups before and after the intervention ( $p>0.05)$, although it was a significant difference in the mean score for analysis of the two groups (control and intervention) before and after the intervention $(\mathrm{p}<0.05)$ : see Table 3.

\section{DISCUSSION}

This study is the first of its kind to be conducted in Palestine. It utilized a randomized controlled design since it applied an interventional program and sought to identify the differences before and after this program via online methods. The study results displayed that there were no statistically significance differences within groups in the majority of study domains, such as student satisfaction, interaction and collaboration and learning autonomy. Our study results thus provide evidence that the distance educational method is effective in the education and learning system in terms of understanding, remembering and some of the processes required in the systematic stages of education, as there were no substantial differences within and between the two methods (online and face-to-face), which means that student in online courses showed a good result in conjunction with face to face group. This study results were found to be Consistent with study of Ekwunife-Orakwue and Teng (2014) where they explored that, no such difference between online and face to face courses, with few direct meetings, which leads to the importance of "blended learning courses, with more direct meetings. The results in Table 3 show that the majority of comparative domains that have been used as parameters to differentiate between online and face-to-face methods are not different before and after the proposed intervention.

The current technology plays an indispensable part in giving a learning background that is close to a face-toface class despite learners' physical separation from the instructor and other learners. Distance learning has become possible because of technology, and these results indicate that communication tools used in the distance learning situation connect both time and physical dimensions to close the students and faculty as a virtual group. The implication of technology enormously encourages and improves the communication not only between teachers and students but also among students. Consequently, the effective and efficient implication of technology in delivering Web-based courses is of critical importance for learning. It demonstrates that students want to use interaction tools to make their learning easier and more efficient and allow them to learn anywhere and at any time.

Instructors teaching via online methods should have the abilities and skills to adapt the basic and advanced requirements that they use during face-to-face methods. Moreover, instructor could help and support the students throughout the distance learning process. This comes in conjunction with Lewis (2011) and he described that for student satisfaction, learner-teacher interaction is a good predictor. As other research suggested that instructors integrate the communication with learners using learning platform and give support and feedback. The statistically significant difference presence within the intervention group for the domain of instructor support may be attributed to the nature of the intervention idea. The instructor might have found some barriers in dealing with students, and the students might also have encountered some barriers during communication with their instructor. Further, it is important not to forget that this intervention and this program were applied for the first time in Palestine, and specifically in the Gaza Strip: thus, it is normal for some initial technical and managerial problems to emerge in the implementation of the proposed idea. 
In the present study, instructor support did not change before and after the intervention within or between the two groups. This issue is very important because the absence of instructor support would create substantial problems regarding distance education for the majority of students. Evidence for this is provided by Kirmizi (2014), who found a modest level of association between interaction and student collaboration, active learning, student autonomy, personal relevance, educator support and authentic learning.

Some previous studies have stated that distance education has several advantages, such as reducing travel costs and time, collaboration with and access to expert professionals expanding opportunities at a worldwide range, and a flexible approach that enables students to access courses and their contents at their convenience (Finch \& Jacobs, 2012). Which is more needed in the Gaza strip, where there is a massive siege that restricts all aspects of daily life, including education and travel, this method would be greatly beneficial for students who do not have the ability to travel for education, especially in educational specialties that are not available in the Gaza Strip but are available on the other side of the same country (West Bank). This area has numerous important educational courses and programs that unfortunately cannot be reached due to the so-called Israeli checkpoints and barriers that have been imposed upon and between Palestinian areas, as well as the continuous closure of the Rafah border crossing, which is the only point at which the Gaza Strip is accessible to the outside world.

Our study results are consistent with previous results such as those of Bell and Fedeman (2013), who concluded that the broad range of different technological advancements utilized by universities during online courses can improve the communication not only between learners and instructors but also among learners. This was achieved in our study and has had a substantial benefit, in that the anonymous nature of the online environment is favorable to shy and anxious students who are reluctant to participate directly in classes, as it enables them to join online programs where they do not have to see each other physically.

The absence of statistically significant differences between the two considered groups after and before the interventional program grants this study a sense of Success. Its results provide huge support for distance learning and encourage its implications by universities in the Gaza Strip during the imposed siege, since some prior investigations have clarified the strong association between sense of community, social interaction and success in distance learning (see, for example, Bryant \& Bates, 2015; Yang, Kinshuk, Yu, Chen, \& Huang, 2014). Moreover, our results are consistent in some ways with those reported by Judrups (2015), who concluded that knowledge management and distance learning bring both disciplines closer and support integration. Model analysis assured several integration approaches.

Moreover, our study results support the claims that have been constructed in earlier literature and research regarding the application of distance learning theories in the design and instructions for distance learning. For example, Yu (2015) stated that students' satisfaction was positively associated with self-regulation, self-efficacy and interaction during distance education. Also, Choy and Quek (2016) reported an imperative direct association between continuous academic-related online performance, satisfaction and cognitive elements.

In Gaza Strip, there is only one culture: this may provide clarity and support for the positive results revealed by this study which was found to be in conjunction with Bordelon (2013) that reported a positive relationship between achievement and satisfaction and suggested that this might be due to cultural differences in learners' satisfaction. Furthermore, our study methods and materials have granted the learners a sense of support and met their expectations; this issue was considered pivotal in the study conducted by Mahle (2011), who suggested that the association between student satisfaction and interaction happens when perceived performance meets learners' expectations.

The results obtained in the achievement test as shown in Table 4 reveal that there is NSD in mean scores in the majority of domains, such as remembering, understanding, and application, between the two groups before and after the intervention, whereas it is a significant difference in the mean analysis scores between the intervention and the control group before and after the intervention. The absence of significant differences provides strong support for the intervention, since the main aim of the achievement test was to support the study results in the three domains examined in Table 3. The results obtained in the achievement test reflect that students were satisfied during the distance education process and felt as comfortable as the control group, since there was NSD between the control and the intervention group in the three domains mentioned above. The significant difference in the domain of analysis between the control and the intervention group may be ascribed to the fact that some learning processes cannot be achieved via online methods or may need to be re-investigated and re-tested in future studies.

A limitation of this research is that the findings did not show higher results in student's satisfaction and learning autonomy in the distance learning group, as there was NSD between the two groups (distance learning and face to face group). It isn't acknowledged whether the transactional distance for online components of a program were seen due to the assigned discussion contents, the discussions design, the course design used through Moodle, "which is considered to be the first experiment in the Gaza strip", the teachers online skills, or if combining different factors to produce the resulting dissatisfaction. 
Further research should be conducted in the strip, to enrich the distance learning experience to students, considering conduction a free workshop on distance learning for both students and instructors.

\section{CONCLUSION}

The distance education is a teaching technique which make the students and instructor separated physically or by time. Normally students use different type of materials, such as electronic media, references, books and CDROMs instead of face-to-face learning, these materials and contents are basically instructed by the technology.

In addition, they are also frequently designed for the ease of the online technology system. Further research should explore ways to improve and develop intellectual rigidity and encourage informed and individual perspectives and determine how to apply technology to involve learners in ongoing and multiple discussions in different online courses. Additional investigation is required to determine how group designs can influence the sense of community learning and social interaction in light of learning styles, skill levels, different personalities and group members. Earlier studies have focused primarily on postings by participants. Using the current technological developments, more research is required to explore different technological elements role in engaging more operative social interaction and fostering a sense of learning communities such as video or audio conferencing using Skype and Google Hangouts, virtual reality and social media network environments.

The researcher has applied the theories and strategies of distance learning to contribute the first distance learning research and endeavor in Palestine. This will aid higher education institutions to increase students' satisfaction with full online courses based on Moore's transactional distance learning and to measure students' autonomy and satisfaction through the Moodle system. Many issues need to be examined in the process of understanding the best practices to be applied to enhance distance teaching and learning.

\section{REFERENCES}

Ali, A. (2011). Key factors for determining students' satisfaction in distance learning courses: A study of Allama Iqbal Open University. Turkish Online Journal of Distance Education, 12(2), 114-127.

Bell, B. S., \& Fedeman, J. E. (2013). E-learning in postsecondary education. Future Child, 23(1), 165-185. https:// doi.org/10.1353/foc.2013.0007

Bordelon, K. (2013). Perceptions of achievement and satisfaction as related to interactions in online courses (PhD dissertation), Northcentral University.

Bryant, J., \& Bates, A. J. (2015). Creating a constructivist online instructional environment. TechTrends, 59(2), 17-22. https:/ / doi.org/10.1007/s11528-015-0834-1

Choy, J, \& Quek, C. (2016) Modelling relationships between students' academic achievement and community of inquiry in an online learning environment for a blended course. Australasian Journal of Educational Technology, 32(4). https:/ / doi.org/10.14742/ajet.2500

Ekwunife-Orakwue, K. C., \& Teng, T. L. (2014). The impact of transactional distance dialogic interactions on student learning outcomes in online and blended environments. Computers $\mathcal{E}$ Education, 78, 414-427. https://doi.org/10.1016/j.compedu.2014.06.011

Finch, D., \& Jacobs, K. (2012). Online education: Best practices to promote learning. Proceedings of the Human Factors and Ergonomics 56th Annual Meeting. https:/ / doi.org/10.1177/1071181312561114

Garrison, D. R. (2011). E-learning in the 21st century: A framework for research and practice (2nd ed.). New York, NY: Routledge.

Gartner, S. (2014). Online Grading to Make Teaching Life Easier with Moodle. Learning Management Systems. Retrieved from https:/ / elearningindustry.com/online-grading-make-teaching-life-easier

Gartner. (2012). Gamification: engagement strategies for business and IT. Report G00245563

Gasevic, D., Kovanovic, V., Joksimovic, S., \& Siemens, G. (2014). Where is research on massive open online courses headed? A data analysis of the MOOC Research Initiative. International Review of Research in Open and Distance Learning, 15, 5, 134-176. https:/ / doi.org/10.19173/irrodl.v15i5.1954

Hanson, D., Maushak, N. J., Schlosser, C. A., Anderson, M. L., Sorenson, C., \& Simonson, M. (1997). Distance education: Review of the literature (2nd Ed.). Washington, DC: Association for Educational Communications and Technology.

Harasim, L. (2012). Learning theory and online technologies. New York, NY: Routledge.

Hillman, D. C. A., Willis, D. J., \& Gunawardena, C. N. (1994). Learner-interface interaction in distance education: An extension of contemporary models and strategies for practitioners. American Journal of Distance Education, 8(2), 30-24. Retrieved from https:/ / moodle.com/partners/. https:/ / doi.org/10.1080/08923649409526853 
Jacobs, G. M., Renandya, W. A., \& Power, M. (2016). Learner autonomy. In G. Jacobs, W. A. Renandya and M. Power (eds.), Simple, powerful strategies for student centered learning. New York: Springer International Publishing. https:/ / doi.org/10.1007/978-3-319-25712-9_3

Judrups, J. (2015). Analysis of knowledge management and e-learning integration models. Procedia Computer Science, 43, 154-162. https:/ / doi.org/10.1016/j.procs.2014.12.021

Kirmizi, O. (2014). A study on the predictors of success and satisfaction in an online higher education program in Turkey. International Journal of Education, 6(4), https:/ / doi.org/10.5296/ije.v6i4.6322.

Language packs - Moodle Docs. (n.d.). Retrieved from https://docs.moodle.org/33/en/Language_packs

Lee, S. J., Srinivasan, S., Trail, T., Lewis, D., \& Lopez, S. (2011). Examining the relationship among student perception of support, course satisfaction, and learning outcomes in online learning. The Internet and Higher Education, 14(3), 158-163. https:/ / doi.org/10.1016/j.iheduc.2011.04.001

Mahle, M. (2011). Effects of interactivity on student achievement and motivation in distance education. Quarterly Review of Distance Education, 12(3), 207-215.

Means, B., Toyama, Y., Murphy, R. \& Baki, M. (2013). Evaluation of Evidence-Based Practices in Online Learning: A Meta-Analysis and Review of Online Learning Studies. Structure. U.S. Department of Education Office of Planning, Evaluation, and Policy Development Policy and Program Studies Service.

Moodle Partners. (2016). Global Certified Service Providers. Moodle. Moodle.com. Retrieved from https:// moodle.org/mod/forum/view.php?id=8067

Moodle Partners. How do the Moodle Partners work? Retrieved from https:/ / moodle.org/mod/forum/view.php?id=8067

Moore, M. G. (1983). The individual adult learner. In M. Tight (Ed.), Adult learning and education. London: Croom Helm.

Moore, M. G. (1997). Theory of transactional distance. In D. Keegan (Ed.), Theoretical Principles of Distance Education. New York: Routledge.

Moore, M., \& Kearsley, G. (2005). Distance education: A systems view. Toronto, ON: Nelson.

Paechter, M., Maier, B., \& Macher, D. (2010). Students' expectations of, and experiences in e-learning: their relation to learning achievements and course satisfaction. Computers $\mathcal{E}$ Education, 54(1), $222-229$. https:/ / doi.org/10.1016/j.compedu.2009.08.005

Simonson, M., Schlosser, C., \& Orellana, A. (2011). Distance education research: a review of the literature. Journal of Computing in Higher Education, 23(2), 124-142. https:/ / doi.org/10.1007/s12528-011-9045-8

Song, L., Singleton, E. S., Hill, J. R., \& Koh, M. H. (2004). Improving online learning: student perceptions of useful and challenging characteristics. Internet and Higher Education, 7(1), 59-70. https:// doi.org/10.1016/j.iheduc.2003.11.003

Stanley, A. (2014). Technology that puts the classroom in students' laptops. Retrieved from https:/ / www.theglobeandmail.com/news/national/education/technology-that-puts-the-classroom-instudents-laptops/article21627186/

Sutton, L. A. (2001). The principle of vicarious interaction in computer-mediated communications. International Journal of Educational Telecommunications, 7(3), 223-242. Retrieved on October 17, 2017 from https://www.learntechlib.org/p/9534/.

Vonderwell, S. (2003). An examination of asynchronous communication experiences and perspectives of students in an online course: a case study. Internet and Higher Education, 6, 77-90. https:/ /doi.org/10.1016/S10967516(02)00164-1

Walker, S. L., \& Fraser, B. J. (2005). Development and validation of an instrument for assessing distance education learning environments in higher education: the Distance Education Learning Environments Survey (DELES). Learning Environ. Res., 8, 289. https:/ / doi.org/10.1007/s10984-005-1568-3

Yang, J., Kinshuk, Yu, H., Chen, S.-J., \& Huang, R. (2014). Strategies for smooth and effective cross-cultural online collaborative learning. Educational Technology E Society, 17(3), 208-221.

$\mathrm{Yu}$, Z. (2015). Indicators of satisfaction in clickers-aided EFL class. Frontiers in Psychology, 6, 587, https://doi.org/10.3389/fpsyg.2015.00587 
Zhao, Y., Lei, J., Yan, B., Lai, C., \& Tan, H. S. (2005). What Makes the Difference? A practical analysis of research on the effectiveness of distance education. Teachers College Record, 107(8), 1836-1884. https:/ / doi.org/10.1111/j.1467-9620.2005.00544.x

Zhu, C. (2012). Student satisfaction, performance, and knowledge construction in online collaborative learning. Educational Technology \& Society, 15(1), 127-136.

\section{http://www.ejmste.com}

